\title{
Affordances of Equality: Ranciere, Emerging Media, and the New Amateur
}

\section{Kurt Thumlert}

To cite this article: Kurt Thumlert (2015) Affordances of Equality: Ranciere, Emerging Media, and the New Amateur, Studies in Art Education, 56:2, 114-126, DOI: 10.1080/00393541.2015.11518955

To link to this article: https://doi.org/10.1080/00393541.2015.11518955

曲 Published online: 25 Nov 2015.

Submit your article to this journal $\asymp$

Џll Article views: 123

Q View related articles $\sqsubset$

View Crossmark data

4 Citing articles: 1 View citing articles 


\section{"Yet, what}

may really spin

the 'wired'

classroom off its

old curricular

moorings is

when equality is

introduced into

the technical

equation."
Affordances of Equality: Rancière, Emerging Media, and the New Amateur

\section{K U R T T H U M LER T}

York University

This article extends a recent educational engagement with the work of Jacques Rancière by linking his meditations on 19th-century worker emancipation to present cultural contexts and media forms. Taking Nick Prior's (2010) notion of the "new amateur" as point of departure, I argue that new media and attendant production contexts offer an unprecedented occasion for rethinking the educational experiments of Joseph Jacotot (the subject of Rancière's The Ignorant Schoolmaster, 1991). By bringing Jacotot's "method of equality" into relation with present forms of cultural production, I elaborate a notion of affordances of equality that updates Jacotot's practice of "experimenting with the gap between accreditation and act" (Rancière, 1991, p. 15) - a method that invited learners to improvise in the gap between an expert role and a talent imitable by anyone at all. In conclusion, I ask what educational theory might learn from the new amateur, from the emerging media these amateurs are engaging, and from the production literacies they enact.

Correspondence regarding this article may be sent to the author at kthumlert@edu.yorku.ca 
1 'll begin this article about art, education, and equality by linking two distant figures. The first-and closest-is the figure of "the new amateur," what Nick Prior (2010) called the self-sufficient, high-tech cultural producer of our digital age. In Prior's formulation, the new amateur exerts, within emerging sociotechnical networks, a mode of creative agency that actively challenges traditional boundaries between specialists and nonexperts. The second figure is that of Joseph Jacotot, a 19th-century educator who formulated a notion of intellectual emancipation based on the supposition of the equality of intelligence. Jacotot devised a method of equality that detached learners from developmental curricular forms, enabling them to directly engage authentic artistic/intellectual challenges. In so doing, this method invited students to undertake an embodied learning adventure that was, as such, more fully their own.

By forging a link between these two figures, and between past and present modes of cultural production, I argue that the new amateurs that Prior describes-and the emerging media these actors are appropriating-offer an unprecedented context for rethinking the ideas of Joseph Jacotot (as recounted in Jacques Rancière's The lgnorant Schoolmaster, 1991).

The central issue I address, as Nick Prior (2010) identified, revolves around how new media are "opening up creative agency and unhooking it from place" (p. 401) and, in turn, challenging the boundaries between professional and amateur, expert and nonexpert ( $p$. 406). By fixing the new "amateur" in quotes, Prior signaled a clear distancing from of the pejorative connotations associated with the word (where to establish an actor as an amateur is, arguably, to demarcate boundaries, or consign a body to "its place" of relative noncompetence). To performatively identify an actor (or oneself) as an amateur, in this context, is to classify the person as an un(der)qualified novice, or marginal actor, lacking in professional knowledge, skill, or taste (Richmond, 2008).

By contrast, I argue that Jacotot's educational writings, as extended by Rancière, ${ }^{1}$ prefigure a notion of the new amateur in ways that actively recharge this term with all of its amorous, participative, and role-blurring possibilities. That is, Rancière/Jacotot renewed the largely forgotten positive etymology of the "amateur as a lover" (Richmond, 2008, p. 82) and, more distinctively, as an "unauthorized lover" (Rancière, 2006; Rugo, 2012). In recounting Jacotot's story, Rancière identified a method of equality that invited novice learners to experimentally engage the same challenges, or enact the same talents, as accredited bodies. The aim of this method was to unlock the creative capacities of anyone from any determinate (curricular) place. What is mobilized here, I argue, is the concept of the amateur not as a social identity, but as a deeply engaged mode of agency through which unauthorized or unqualified actors (Rancière, 1998, 2003) might unexpectedly take part in authentic aesthetic/ intellectual practices-out of place. By tracing links between Jacotot's old method and this new amateur, I argue that what is on offer for educational theory are not only educationally productive relations to emerging media, but also a mode of learning agency that challenges-and helps us critically rethink-traditional curricular 
forms, as well as the conventional educational role-relations and techniques sustained within those forms.

\section{Amateur and Explication: Distributions of the Sensible}

In The Ignorant Schoolmaster, Rancière (1991) dramatized the story of Joseph Jacotot, a professor-in-exile who discovered he could teach what he did not know, precisely because he-a French speaker-did not share the same language as his Flemish students. Since he could not, strictly speaking, instructionally act upon his students, Jacotot instead asked them to teach themselves using a specific technology: a polyglot edition of an epic adventure with the two translations running alongside one another. He then asked that his students write, in French, what they thought about the text. By groping hit-and-miss, and by improvisationally working between the two translations, Jacotot's students-through their own individual and collectively sourced powers - astonished Jacotot with their unanticipated accomplishments. Through this chance experiment, Jacotot discovered that it was not necessary for him to explain his knowledge of the text, nor was it necessary for him to guide his students, step-by-step, to a significant learning outcome.

In turn, Jacotot saw that educational methods, when presupposing student incapacity as the educative starting point and making the teacher's knowledge and know-how the objective to be ultimately reproduced, delimited what learning bodies might do and narrowly restricted what talents might be enacted.

Jacotot called this educational technique explication. The method of explication, by first placing the student in unequal relation to the teacher, instantiates what Rancière (1991) called an "imaginary distance" (p. 9) between the place of the capable (those who know) and the place of the incapable (those who do not). As Rancière argued, pedagogies of explication work forward from the teachers' knowledge of ignorance. This is not, however, the educators' knowledge of their own epistemic limits but, rather, the technical understanding of the inabilities of the student. Equipped with this kind of disciplinary knowledge (Foucault, 1995), educators may address students in their place (of relative lack) and the method of explication progressively closes the gap between the perceived incapacity of the student and the presumed knowledge or know-how of the teacher/specialist. Through the educational arc, however, the epistemic authority of the teacher and the inferior position of the learner are indefinitely sustained in coconstitutive relation to one another.

What's at stake is that the pedagogical medium is the message: alongside whatever the knowledge or know-how that is taught in schools is the lesson of "stultification" (Rancière, 1991, p. 13): the embodied message that one cannot act, imagine, think, or do without guidance-predicted environments, calculated sequences, and developmental scaffolding, all of which become enduring, disciplinary fixtures of an educative process that, so Rancière argued, continuously implicates students within a dependent "circle of powerlessness" (p. 15).

But as Jacotot argued, the method of explication was founded upon a "pedagogical fiction," a founding premise that divides the intelligence into two (p. 7)-into divisions between ignorance and knowledge, novice and expert. The pedagogical fiction both prefigures and enacts an allocation of ranks and relational actor-positions, mobilizing what Rancière (2004) called a distribution of the sensible: a seemingly self-evident distribution of identities and places, capacities and talents, where inequality is rationalized into a given world of experience and practice.

Rancière (1991) insisted, however, that explication's distribution of the sensible is more than a discrete arrangement between teachers and students, between those who educate and those who are "the subject" of an education. Rather, it is coextensive with integral systems of social pedagogization (p. 120); coextensive with wider methods of "social progress" (p. 134) that 
operationalize to (re)identify, better understand, and more efficiently reduce inequalities-and thus infinitize relations of inequality through the technocratic management and amelioration of them. The reduction of inequality implies both the simplification of challenges to the expected level of the student or social actor, as well as the curricular means of progressively "abolishing the distance" between the presumed incapacity of the student and the knowledge or know-how of the specialist (Rancière, 1991, p. 5; Rancière, 1995a, pp. 52-54). The project of reducing inequality configures an alwaysreiterable distance where curricular "fragments" of learning are detached from wider ecologies of meaningful practice, are canalized into contiguous stages based on the principle of "necessary antecedence" (Whitehead, 1929, p. 16), where the student is called to steadily follow "a master with whom he [sic] will never catch up" (Rancière, 1991, p. 21). For as long as the method of explication is enacted, the same relations of inequality are restaged, the same asymmetrical roles performatively occupied, and learning actors are indefinitely separated from their own possible capacities (Rancière, 1995a, p. 84).

Seen in this way, the method of explication continues to inform our most commonplace curricular techniques of capacity and knowledge building in schools (Cornelissen, 2010; Stamp, 2013). Explication is writ large today through the corporatization of schooling environments where macroinstitutional imperatives for standardization increasingly (re)define and administrate everyday purposes, practices, and microrelations in classrooms. In order to address (infinite) crises in student underachievement-or in order to more seamlessly align schooling purposes and goals with economic imperatives and functions of workplace employability (Peters, 2010) — what is galvanized, continuously, are top-down means and measures to enhance extant curricular forms and practices. This describes a corporate educational enterprise that increasingly maps segmented learning outcomes, distributes classifiable bodies accordingly, and scripts the very means in which preprogrammed outcomes are to be best obtained and assessed. In the service of accountability and transparency, these practical scripts, role-relations, and standards of progress and improvement are universalized within and across institutions. ${ }^{2}$

What is codified, (re)scripted, and endlessly perfected here is explication's distribution of the sensible: the traditional role-relations between those who know and those who do not, the predetermination of "significant learning," and curricular divisions between professional knowledge and the very means of knowledge making and cultural design. What is at stake is that embracing technologies of explication have their (unintended) performative effects: Students indefinitely occupy positions of relative lack and so embody the place of the incapable (Rancière, 1991, p. 21). The pedagogical fiction reiterates its own distribution of the sensible: Even as students make progress, they may never act-or perceive themselves as acting —in maker roles, as agents involved in framing their own situations, in actively reconfiguring their own worlds. Students in this way accrete segmented skill sets and inert knowledge about "states of affairs over which they themselves have neither any agency nor any embodied competence" (de Castell, Jenson, \& Thumlert, 2014, p. 16).

Stripping all that is ludic, ardent, or amorous from the word, amateur, the method of explication, as articulated by Rancière, asks learners to identify themselves as just that: the (abject) subject of a pedagogical fiction.

\section{Im-Personations: The Gap Between Accreditation and Act}

In The Ignorant Schoolmaster (1991), Rancière wrote that "explication is not necessary to remedy an incapacity to understand... [on the contrary] it is the explicator who needs the incapable and not the other way around; it is he [sic] who constitutes the incapable as such" ( $p$. 6). Alternately, what Rancière invoked through 
Jacotot's story was a method of equality where the capacities of the learner can be unlinked from any disposition, or curricular place, characterized by developmental lack. If the method of explication assumes the inequality of intelligence and works to reduce the difference, Jacotot's method begins with the supposition of the equality of intelligence, with the aim of verifying intellectual equality in every circumstance. The aim of this method is to "reveal an intelligence to itself" (p. 28) in ways where a learning agency and the experience of self-efficacy are implicated within the self-same practical circuit of capacity, or "circle of power" (p. 15).

Jacotot's founding supposition-intellectual equality-is based on a still-radical notion of intelligence. For Jacotot, intelligence is not a quantifiable substance or essential property that resides within the heads of learning actors. Rather, intelligence is a function of the degree of volitional energy or sustained attention (p. 25) directed toward a present challenge. If Jacotot is able to posit that intelligence is equal, as a working supposition, it is because one does intelligently by virtue of the intensity of want, will, or desire that is exerted in relation to a present challenge or a meaningful practice (p. 51).

To verify this equality of intelligence and to "suppress the imaginary distance [between capable and incapable] that is the principle of pedagogical stultification" (p. 9), Jacotot put into play situations where students were enabled to "experiment in the gap between accreditation and act" (p. 15). What Jacotot did was permit novice learners to improvisationally engage the same resources and technologies, and to experimentally do the same things, as "the master." Borrowing a term from Gallop (1995), this playing in the gap between accreditation and act invites learners to im-personate the accredited, and to thereby actively appropriate the gestures and talents of those with symbolic authority or credentialed status. What im-personation makes intelligible is an agentive, mimetic connection between playing make-believe-the embodied performance of a talent that is "not yours," not proper to your expected place-and a genuine competence that might be enacted for real.

Drawing on the work of Judith Butler, Pelletier (2009) argued that Rancière's work can be viewed through a similar performative lens where, through the appropriation of the gestures and signs of one's "social betters," subordinate actors could performatively unlock themselves from a (class) identity and its corresponding horizon of possible (contained) agency. Rancière (2004) called this unhooking from place dis-identification. As a means of declassifying oneself from an imposed identity, status, and corresponding place, dis-identification takes place through acts that demonstrate equality, through unanticipated performances that challenge stable, hierarchical roles and classifications for bodies.

To clarify, experimenting with the gap between accreditation and act does not imply placing an amateur behind the wheel of a jetliner (though, clearly, increasingly feedback-rich simulation environments establish near-authentic game conditions for engaging such deep challenges). The yet more fundamental point, and the most powerful aspect of Rancière's intervention, is to see what effects might be produced and what capacities engendered when the intellectual equality of anyone is, from the outset, presupposed and supported. The aim, then, is to see what talents might be performatively assumed when students, no longer bound to a scripted curriculum, are invited to play "the same game" as the master (Rancière, 1995a, p. 49).

In his archival research on 19th-century worker (self)emancipation, Rancière (1989) articulated the stakes of this game when he suggested that:

A worker who had never learned how to write, and yet tried to compose verses to suit the taste of his times, was perhaps more of a danger to the prevailing ideological order than a worker who performed revolutionary songs. (p.xxix)

In The Nights of Labour (1989), Rancière chronicled workers who dreamed of moving "to the 
other side of the canvas" (p. 5), and who, thence, made themselves unauthorized "apprentices in a common culture" (p. xxix). By "reading and recopying, decomposing and recomposing, the few texts that one had managed to expropriate from the patrimony of the literate" (Rancière, 1989, p. 165), these "illiterate poets" arrogated to themselves the signs, gestures, and symbolic capacities of artists, poets, and philosophers. Here, some of the media that these workers used to teach themselves were discarded books, the pages of which were being used by merchants to wrap up food products. Repurposing this food packaging into their own educational media, and by exchanging chance texts and diverse aesthetic artifacts amongst themselves, Rancière chronicled how these workers, using whatever free time they could mobilize, set for themselves the stage of their own intellectual/ aesthetic adventures. In consonance with the positive etymology of amateur, these workers described the affective tone of their own aesthetic and educational trajectories as "voluptuous," "magnetic," and "incandescent" (Rancière, 1989, pp. 79-83).

Rancière (2003) described these acts as "appropriation[s] of equality," each a sudden "taking part" in intellectual and cultural practices "whose privilege others had reserved for themselves" (p. 223). Through acts of im-personation, as it were, Rancière's workers asserted themselves as players in a common game: They enacted positions of intellectual competency, political speech, and artistic expression that challenged the prevailing distribution of the sensible about which bodies could think, aesthetically apprehend, or artistically do. Rancière's workerartists not only repudiated their given functions as "just workers," but also refused incorporation into utopian collectives or emancipatory projects as devised by experts who would think, plan, and speak for them. These role-blurring acts reflect upon what is, for Rancière (2003), an untimely question: "How those whose business is not thinking [or not doing aesthetically] might assume the equal authority to think and thereby constitute themselves as thinking subjects" (p. $x x v i)$; that is, as actors sharing a common world of art, invention, and argument.

\section{The Affect of Adventure: Amateur and Serious Play}

Linking Rancière's 19th-century narratives to contemporary contexts and to the new amateur, what are the present means and media forms that invite learners to improvisationally engage practices characteristically assigned to accredited bodies? What are the emerging media and production contexts through which the amateur might seriously apprehend/engage artistic and cultural artifacts and be challenged to produce authentic artifacts in their own right? And what are the educational stagings and supports (both social and technological) that enable those without qualification to take part, to count themselves among the capable, and to say things like Me too, I'm an artist (Rancière, 1991, p. 67)?

Lave and Wenger (1991) articulated a notion of situated learning that, I suggest, can be reconceived for emerging media ecologies. Explored here are educational forms and communities of practice where meaningful learning takes place outside of "the structure of pedagogy as the source of learning" (p. 113). Rhetorically, Lave and Wenger opposed the traditional teaching curriculum to what they call a learning curriculum. Whereas the former method is based on "strongly asymmetrical" master-apprentice relations (p. 93) where teachers sequence contiguous lessons in the service of gradually obtaining known outcomes, the learning curriculum provides immediate, hands-on access to authentic means, media, and challenges. And if the teaching curriculum "structures resources" and "controls access" to experiences (where representational meaning is mediated by the "instructor... with an external view of what the knowing is about"), the learning curriculum "consists of situated opportunities for the improvisational development of a new practice," opportunities which are "not constructed for the instruction of newcomers" (pp. 96-98). Insofar as novices are 
not addressed as such, the learning curriculum suppresses the inaugural gesture of the explicator to solicit the "amateur" (pejorative inflection) in the place of incapacity/ignorance.

In a discussion that links emerging media to a notion of ludic epistemology, de Castell (2011) similarly argued that the traditional curriculum suffers from a near "pathological addiction" (p. 25 ) to script-driven, language-based practices that incrementally mediate-and continually mitigate-hands-on learning performances and the type of affective and ludic energies that are released by the latter. The traditional curriculum, in de Castell's view, has driven a wedge between learning and pleasure, learning and play, "ignoring sound, body, affect, and material environment" (p. 24) while systematically disengaging learning from the world in ways that divide learners from meaningful participation in an unfinished world of art, knowledge, and practice. Contesting such a curriculum, as well as commonly received notions of what counts as knowledge in schools, de Castell envisioned aesthetically multimodal forms of intellectual engagement that revitalize "play and pleasure as critical curricular elements" (p. 25).

Put otherwise, the business of thinking and learning might be recognized as a libidinal affair before being framed as a "semiological activity" (Weiss, 1988, p. 70). As de Castell (2011) reminded us, the Latin word ludus embraced both learning and play. And as Caillois (1962) argued, while "the proper end of play is never to develop capacities... the aptitudes it exercises are the very same as are used for study and serious adult activities" (p. 167). What Caillois suggested, and what de Castell directly argued in relation to new media, is that serious play, as a situated mode of experimental/exploratory and mimetic learning - that up to recently has been relegated to the very young (Lillard, Pinkham, \& Smith, 2002)—-might be fruitfully reconfigured as a significant mode of educational experience for all (de Castell et al., 2014).

Improvisation and serious play are, in fact, common threads that link Jacotot's experiments in equality to both the learning curriculum and ludic epistemology. Improvisation was one of Jacotot's "canonical exercises" (Rancière, 1991, p. 64). It not only provided a vital context for learners to adopt patterns of action and creatively remediate forms of representation; it also enacted a staging where those without accreditation could performatively act the part of the qualified and actively wrangle with the same challenges, the same production talents.

In "the act," so Rancière argued, is where intelligence lies; in the immanent "flux and reflux of perpetual improvisation" (p. 64). As Rancière punctuated this agentive notion of intelligence, "wanting was all that was necessary for doing"; understanding is "the work of the will" (p. 57), a coefficient of attention (p. 51).

The kind of wanting Jacotot saw as pivotal to significant learning is not in want of something absent-a lack to gradually, episodically redress-but makes present a mode of engagement where exhilaration, pleasure, and novelty are immanent to the learning operation and continuous with what a learner is absorbed in. Wanting, as de Castell (2011) suggested, implies engaged self-direction towards more; that is, a longing beyond what we presently have mastered. This shifts the curricular emphasis from what is to be known toward affective experiences that invite involvement as adventure and that support the visceral rush of exceeding prior limits (Caillois, 1962; de Castell, 2011; Gee, 2004). Significant learning might, in this light, be reconceived in affective terms as a function of adventure, a voyage open to wonders, mysteries, and the allure of real-world stakes (Egan, 2007; Peters, 2010; Whitehead, 1929).

Rancière (1995b) took affect into account as a mobilizing (political) variable precisely when he argued that want or "eagerness" is "the common failing of those who do what they have no place to do" (p. 18). Rancière (1995a) highlighted an incandescent mode of involvement that is charged, and rhythmically recharged, by the immanent pleasure of feeling oneself within capacity, where the energies of 
equality "are engendered and augmented by their own actualization" (p. 50)

\section{Generous Media: Affordances of Equality}

To maintain ranks, wrote Rancière (1991), "the improvisations of incompetents must be avoided" (p. 121). What I would like to call an affordance of equality is any media form or technology that supports precisely that-improvisation by anyone; the experimental enactment of common talents and artistic capacities that are, as such, the property of no one in particular, or of anyone at all. If equality ${ }^{3}$ is, in Rancière's idiom, a supposition to be tried/verified, then an affordance of equality can be seen as an improvisational (any)thing that invites an (unclassified) actor to engage a common production tool, in a maker role, while challenging the division between child's play and an official competency.

Here, Prior's notion of the new "amateur" allows us to link Jacotot's old techniques of equality to new social relations and emerging media ecologies. As Prior (2010) argued, it is through these media that those formerly "considered non-specialists are actively producing" genuine cultural and aesthetic products; in so doing, these actors are "threatening the very boundaries around professional and amateur, expert and non-expert, so central to modern social configurations" (p. 401).

In going forward, my aim is not to translate Prior's sociological description into a prescriptive use of "educational technologies" in schools. Rather, I am interested in how new media and coemerging production contexts invite and abet serious learning engagements and, thus, support common-and intervening-positions of productive (aesthetic) participation.

I use one recent creation tool, the Tenori-on, ${ }^{4}$ as a concrete metaphor for considering an affordance of equality and how such affordances relate to learning. Using the Tenori-on, actors both make music and do music theory through the immediate, haptic process of designing serious musical artifacts. In media res, (any)one makes music by pressing dots on a digital interface: Players activate or deactivate notes/tones, select voices/instrumentation, explore key signatures, scales, and musical modes; they sample musical phrases or ambient materials; they add or subtract notes, arrange or modify chords and tonal relations, increase or diminish durations, intensities, and velocities; they trigger features like chance operations or sculpt sound visually/ gesturally through a pictorial "drawing" mode. Through hit-and-miss operations, players deconstruct and reconstruct musical forms, composing and recomposing "loops" and "layers" (multidimensional arrangements of melody, harmony, counterpoint, dissonance, rhythm, and ambient sound texture) and sequenced musical "blocks" until one has bodied forth a full-fledged musical work (and one produced, incidentally, in the key of child's play).

As Prior (2010) remarked, emergent all-inone software studios "combine the functions of a range of hardware separates... into a single virtual unit. Whole orchestras-indeed music's whole sonic palette-can be conjured up in these digital spaces, giving rise to new stylistic combinations and borrowings" (p. 400). Meanwhile, websites like SoundCloud offer open-access venues to upload and share works: In short, they announce novel communities of practice-rich networks of multimodal production, publication, and real-time creative collaboration, where peer-to-peer tutorials, as well as diverse aesthetic models and novel techniques, are apprehendable and in play.

Interestingly, these interactive media support experimentation, attention, and learning without imposing a pedagogy of explication (i.e., the teacher's incremental mediation of discrete skill to distant talent, of simple part to mature whole). Faced with an affordance of equality, learners are no longer restricted in proximal relation to what they can do next (with guidance), nor in programmatic relation to a known outcome to be replicated. Competency, as Cazden (1981) put it, is not required in advance of the performance. Rather, the performance- 
the ongoing, improvisational groping along, as Jacotot referred to the process-enacts the competency, proficiency, or talent from within vital contexts of production and situated use.

As with Dewey's (1934) notion of "impulsional action" (p. 60), such engagements imply tensile resistances and strains: modes of interaction that challenge and renew attention. By overcoming obstacles and reconfiguring heterogeneous materials into new relations and forms, impulsional action, so Dewey argued, "eventuates elation" (p. 60)-pleasures that in turn feed back, productively, into the engagement. Though impulsional action is not reducible to any media form, devices such as the Tenori-on invite such sustained modes of interaction/engagement where immediate feedback, re/play, and try-again are internal to the design process. The (learning) medium incites risk-taking and second chances where learners may, under their own power, surpass previous limits-and experience the visceral confirmation of doing so (de Castell \& Jenson, 2007; Gee $2004,2007)$. Self-efficacy is supported by the dynamic, repercussive, trial-and-error processes of attending to something meaningful, or being invested in a course of action that is, specifically, the learner's own learning adventure.

One might characterize an affordance of equality in terms its generosity; that is, in terms of how it invites intuitive, improvisational play, and how it buoys experimental, hit-and-miss operations (e.g., through additive and subtractive processes). Or generosity might be gauged in affective terms, like how an affordance supports the pleasure of apprehending far-flung vistas and unlocking "chance detours" (Rancière, 1991, p. 5); of copying and quoting elements; of inhabiting foreign styles and gestures, and of assembling and remixing elements and styles into fresh combinations, new relations, figures, and forms. To be clear, such production literacies are, in digital contexts, as much socially mediated adventures as they are immersive, technical ones. One makes meanings and forms with others-both human and technological (Latour,
2005) - within the context of appreciably meaningful aesthetic interventions that can be audienced as such.

This is not to say these tools are not without their own implicit constraints on agency, their own encoded scripts, as well as attendant risks to identity or anonymity. Nor by simply supporting an "unpedagogicized" agency (Rancière, 1991, p. 120) do emerging media somehow circumvent the importance of critical reflection by learning actors on the practices they are engaging, on the implicit codes/regulations surrounding any media tool-or how learners themselves might engage in recoding or constructing their own applications. Nor do the most radical affordances of equality circumvent critical negotiation about what is being made, what perspectives are being embodied, or who has access.

With regard to access, however, the issue I am addressing is not just about "high-end" technical innovations. Jacotot's own experiments utilized technologies including lithography, polyglot texts, or any book liberated from the developmental regime of explication.

What is important from the standpoint of educational theory is how the Tenori-on (taken here as a model) takes much that is esoteric-and even unapproachable-about music theory and transforms it into an intuitive, tactile, and (literally) incandescent mode of serious play. Caillois (1962) argued that play tends to remove the very nature of the mysterious or the esoteric; one learns the most serious things through a playing engagement in significant production contexts. In dispelling the esoteric, such "serious play" production pedagogies do more than teach literacy skills or propositional knowledge: They instate involving "process-native" environments where learners are procedurally and mimetically enabled to become different kinds of actors, makers, artists, and designers (Bogost, 2011; de Castell et al., 2014; Juul, 2010; Squire, 2008).

By placing learning actors in maker roles, affordance generosity might be estimated, then, in terms of how the medium supports acts that challenge distinctions between a virtual talent 
and the real thing. The point is not to see all acts, artifacts, or expressions as equal, but to test what is possible under conditions that assume equality from the outset, where learning actors might in fact begin competently and, in so doing, might "affirm themselves as joint sharer[s] in a common world" (Rancière, 1995a, p. 49).

In this light, the DIY "maker" aesthetic surrounding new media is charged by an experimental attitude to art that, like the Fluxus movement decades ago, challenged not only what could be seen as art, but also who could make or do art (Mekas, 2005). Recent films ${ }^{5}$ have examined the relation between Fluxus and contemporary DIY artistic practices, chronicling how nonexperts appropriated-or joyfully misappropriated-whatever media they could get their hands on to do art-from used Super 8 cameras to refunctioned music boxes. What counts, in this argument, is how these unauthorized actors-like Rancière's workers from The Nights of Labour-repurposed professional aesthetic resources, devised extended techniques, or modified outmoded technologies, so as to include themselves as full-fledged artists, regardless of whether they "could or could not" make or do art. Like the semiliterate worker who writes poetry to suit the taste of the times, these actors learned how to play quite competentlyin the most accredited sense of the word-but not until long after they were already competently playing.

\section{Discussion: Follow the Amateurs}

Rancière insisted, across much of his work, that equality and democracy are not simply formal aims to obtain: They are practical relations that can be verified in the material present-through ongoing practices of equality. Therefore, this conclusion does not consider how to adapt technical innovation to the ends of schooling, but considers how formal spaces of learning might be made porous to these affordances of equality and the forms of agency they support. Rather than press new media into the service of conventional ends, why not inves- tigate how learners might-through emerging media and the production contexts they provide-disrupt our most stultifying educational conventions?

Helpfully, in Disrupting Class (2008), Christensen, Horn, and Johnson discern between two ways of perceiving and positioning technical innovations in schools. First, what Christensen called a sustaining technology augments schooling practices without challenging basic suppositions, standard operating procedures, and traditional metrics for measuring "student growth." With a sustaining technology, institutional purposes and demands for standardization press new technologies into the service of enhancing inherited educational techniques and continuing asymmetric role-relations.

Alternately, what Christensen called disruptive innovation arrives laterally, is not recognized by the institution as an ends-efficient means or a cost-effective resource, is open access, is being used or modularly toyed with by actors outside of the dominant system (by nonconsumers of the institution). Disruptive innovation is able to enact itself by virtue of its separateness from the organization, by virtue of not cohering with the prevailing common sense or the organization's means-ends standards of utility, profit, and value. Nevertheless, disruptive innovation is disruptive precisely because it opens up and makes intelligible new planes of performance, competency, and value; new models of action/practice; and new rationale for what counts. Rather than confront dominant institutions head on, disruptive innovation breaks with patterned rituals and role-positions by enacting distinct sets of practice characterized by novel game rules, new modes of play, and different grounds for who can play. Christensen thus envisions habit-breaking innovations that support student-centric exploration with customizable interfaces that permit modal flexibility to "learning style" and engaged self-direction through curricular materials.

Yet, what may really spin the "wired" classroom off its old curricular moorings is when equality is introduced into the technical equation. If I am 
reading Christensen's notion of disruption correctly, then perhaps we should turn our attention to those who are doing the disrupting. Following Latour's (2005) methodological call to "follow the actors," what might educational theory learn from these new amateurs, and from the media affordances these actors are appropriating -or expropriating - to take part as competent players, as serious cultural producers, in a common game? Rather than rely just on the specialized words of experts, Latour urged us to attend to how new media are variously perceived, mobilized, and (re)articulated by everyday users: To follow the actors means to trace "the unexpected" and "surprising connections" (p. 252) between artifacts and actors, between learning pleasures and embodied competences, and to see how these shifting relations may in fact reassemble wider networks of agency and participation. As Prior (2010) noted, one reason monopolies on specialization, proprietary knowledge, and credentialed practice are being challenged today is due to the fact that the material technologies "that once separated amateur and professional now travel between them more readily" (p. 402). Such traveling media, and the DIY postures toward them, are thus disruptive to the traditional curriculum because these innovations are already being competently utilized by "non-consumers" of the educational system (Christensen et al., 2008); that is, by a multitude of amateurs who are no longer heeding the (pejorative) call of that name.

By following these amateurs, what is on offer-and what educational theory might explore-is a learning agency unmoored from the disenchanted world of developmental pedagogy (where bodies are continuously re/positioned "on the way" to competency). What these actors demonstrate is that it may not be a discrete learning style that supports intelligence but, rather, multimodal production literacies; not multiple intelligences, each with its own notational strength, but bricolage: a cross-plaiting of modes, a common (equal) intelligence adventurously involved in, and improvisationally engaged across, the whole register of symbolic-aesthetic forms. Taking another term from Fluxus, what these actors are putting into play is intermedia: the modal interexpression of symbolic codes, aesthetic forms, and communicative genres, where there's no proper starting point for a learning adventure (Rancière, 2009) and no single privileged code (de Castell, 2011).

This article calls for an exploration of how the new amateurs might challenge our most enduring pedagogical fictions. How might their pedagogies of production make intelligible a form of serious learning that unlocks creative capacity from any (disciplinary/curricular) place? What can educational theory learn from a new amateur's own adventures? And how might the notion of a new amateur, as unauthorized lover, be opposed to the amateur who is - through methods of explication-endlessly counted out? Why not further investigate, as Rancière (1989, 1991, 1995a, 2009) variously proposed, how productive equality might be when taken as an initial supposition, as something to support and insistently verify.

\section{A UTHOR NOTE}

I wish to express my sincere thanks to the reviewers of this article. They displayed an exceptional degree of both critical and co/creative engagement with this manuscript. 


\section{REFEREN CES}

Bogost, I. (2011). How to do things with videogames. Minneapolis: University of Minnesota Press.

Caillois, R. (1962). Man, play, and games. (M. Barash, Trans.). London, England: Thames and Hudson.

Cazden, C. (1981). Performance before competence: Assistance to child discourse in the zone of proximal development. Quarterly Newsletter of the Laboratory of Comparative Human Cognition, 3(1), 5-8.

Christensen, C. M., Horn, M. B., \& Johnson, C.W. (2008). Disrupting class: How disruptive innovation will change the way the world learns. New York, NY: McGraw-Hill.

Cornelissen, G. (2010). The public role of teaching: To keep the door closed. Educational Philosophy and Theory, 42(5/6), 530-531.

de Castell, S. (2011). Ludic epistemology: What game-based learning can teach curriculum studies. Journal of the Canadian Association for Curriculum Studies, 8(2), 19-27.

de Castell, S., \& Jenson, J. (2007). Digital games for education: When meanings play. Intermediality: History and Theory of the Arts, Literature and Technologies, 9(Spring), 113-132.

de Castell, S., Jenson, J., \& Thumlert, K. (2014). From simulation to imitation: Controllers, corporeality and mimetic play. Simulation and Gaming, 45(3), 1-24. doi: 10.1177/1046878114542316.

Dewey, J. (1934). Art as experience. New York, NY: Minton, Balch \& Company.

Egan, K. (2007). Imagination, past and present. In K. Egan, M. Stout \& K. Takaya (Eds.), Teaching and learning outside the box: Inspiring imagination across the curriculum (pp. 3-20). New York, NY: Teachers College Press.

Foucault, M. (1995). Discipline and punish: The birth of the prison (2nd ed.). New York, NY: Vintage.

Gallop, J. (1995). Im-personation: A reading in the guise of an introduction. In J. Gallop (Ed.), Pedagogy: The Question of impersonation curriculum (pp. 1-18). Bloomington, IN: Indiana University Press.

Gee, J. P. (2004). Situated language and learning: A critique of traditional schooling. London, England: Routledge.

Gee, J. P. (2007). Good video games and good learning: Collected essays on video games, learning, and literacy. New York, NY: Peter Lang.

Juul, J. (2010). A casual revolution: Reinventing video games and their players. Cambridge \& London: The MIT Press.

Latour, B. (2005). Reassembling the social: An introduction to actor-network theory. Oxford, England: Oxford University Press.

Lave, J., \& Wenger, E. (1991). Situated learning: Legitimate peripheral participation. Cambridge, MA: Cambridge University Press.

Lillard, A., Pinkham, A., \& Smith, E. (2002). Pretend play and cognitive development. In U. Goswami (Ed.), Handbook of cognitive development. London, England: Blackwell.

Mekas, J. (2005). Conversations: Letters, notes, misc. pieces. Vilnius, Lithuania: Lithuanian Art Museum.

Pelletier, C. (2009). Emancipation, equality and education: Rancière's critique of Bourdieu and the question of performativity. Discourse: Studies in the Cultural Politics of Education, 30(2), 137-150.

Peters, G. (2010). Ignorant teachers, ignorant students: Jacotot \& Ranciere in the art school. Retrieved from http:// academia.edu/206845/Ignorant_Teachers_Ignorant_Students_Jacotot_and_Ranciere_in_the_Art_School

Prior, N. (2010). The rise of the new amateurs: Popular music, digital technology and the fate of cultural production. In J. R. Hall, L. Grindstaff \& M-C. Lo (Eds.), Culture: A sociological handbook (pp. 398-407). London, England: Routledge.

Rancière, J. (1989). The nights of labor: The workers'dream in nineteenth-century France. Philadelphia, PA: Temple University Press.

Rancière, J. (1991). The ignorant schoolmaster: Five lessons in intellectual emancipation. Stanford, CA: Stanford University Press.

Rancière, J. (1995a). On the shores of politics. New York, NY: Verso.

Rancière, J. (1995b). The names of history: On the poetics of knowledge. Minneapolis: University of Minnesota Press. Rancière, J. (1998). Dis-agreement: Politics and philosophy. Minneapolis: University of Minnesota Press. 
Rancière, J. (2003). The philosopher and his poor. Durham, NC: Duke University Press.

Rancière, J. (2004). The politics of aesthetics: The distribution of the sensible. London, England: Continuum.

Rancière, J. (2006). Film fables. London, England: Berg.

Rancière, J. (2009). The emancipated spectator. London, England: Verso.

Richmond, S. (2008). Notes on saying and showing, beauty, and other ideas of interest to art and education, with reference to Ludwig Wittgenstein. Paideusis, 17(2), 81-90.

Rugo, D. (2012). The logic of the unauthorized lover: Jacques Rancière's Les écarts du cinema. Senses of cinema. Retrieved from http://sensesofcinema.com/2012/book-reviews/ the-logic-of-the-unauthorized-loverjacques-rancieres-les-ecarts-du-cinema

Stamp, R. (2013). Of slumdogs and schoolmasters: Jacotot, Rancière and Mitra on self-organised learning. Educational Philosophy \& Theory, 45(6), 647-662.

Squire, K. D. (2008). Video game based learning: An emerging paradigm of instruction. Performance Improvement Quarterly, 21(2), 7-36.

Weiss, A. S. (1988). The other as muse: On the ontology and aesthetics of narcissism. In D Allison, P. de Oliveira, M. Roberts \& A. S. Weiss (Eds.), Psychosis and sexual identity: Toward a post-analytic view of the Schreber case (pp. 70-87). Albany, NY: SUNY Press.

Whitehead, A. F. (1929). The Aims of education and other essays. New York, NY: The Free Press.

\section{E N D N O T E S}

1 It is important to signal Rancière's unique authorial relation to Jacotot's educational writings as rhetorically enacted in The lgnorant Schoolmaster (1991). Rather than explain or contemporize Jacotot's work from the authoritative position of social science, Rancière weaves an involving five-act story, mobilizing "theory" through literary narrative, where firm distinctions between Rancière's voice and Jacotot's voice are suspended. The effect is that the message of equality is conveyed, formally, through the medium of expression. As Pelletier (2009) stated, "equality is instantiated in the telling [of the story] itself... no clear distinction is established between the narration of Jacotot's adventures and Ranciere's commentary. The writing effects the collapse between subject and object of knowledge advocated in the narrative" (p. 143). Moreover, definitive connections between Jacotot's historical situation and any given "present" of educational practice are similarly suspended, which invites the reader to adventurously engage or operationalize The Ignorant Schoolmaster as an open text, an unfinished problematic.

2 One might extend Jacotot's notion of explication by noting that teachers are being increasingly recast in the roles of curricular technicians, and in ways that delimit teachers' own creative or interventional capacities. In this sense teachers, too, become the "subjects" of explication.

3 What is at stake here is not equity (as social fairness), but equality as the sameness of a common intelligence, where it is supposed that there is no special place for the intelligence of anyone. The power of Rancière's intervention lies in the practical assumption that equality is something that can be presupposed and verified in the present, rather than as it is traditionally conceived: as a formal social goal to be obtained in the future. Whereas social equity is posed as a project done to or for classifiable social actors, intellectual equality (for Rancière) is something than can be tested, tried, and ongoingly renewed. In Rancière's (1995a) view, the gradualist project of "reducing inequalities" mobilizes hierarchies of intelligence (p. 52), modes of knowing and classifying that make incapacity or lack "explicit," with the consequence that inequalities may be rigidified (p. 54). Rancière's logic of equality can indeed have wider "social effects" (redistributions of the sensible), but not in any preprogrammed or technocratically-managed way. As Rancière (1995a) punctuated this, equality is an initial supposition, or it is nothing at all.

4 Iwai, T. (2006). Tenori-on (Hardware); Tenori-on/TNR-I (for Ipad, iPhone, iPod Touch). Hamamatsu, Japan: Yamaha, Inc.

5 Roworth, V. (Producer), \& Danhier, C. (Director). (2012). Blank city [Motion Picture]. USA. Kino Lorber. Braun, D., Braun, J., \& Crary, S. (Producers), \& Crary S. (Director). (2006). Kill your idols [Motion Picture]. USA: Palm Pictures. 